WORKING PAPER 2/2019

A PROVINCIAL VIEW OF CONSUMPTION RISK SHARING:

ASSET CLASSES AS SHOCK ABSORBERS

Victor Pontines

The South East Asian Central Banks (SEACEN) Research and Training Centre (80416-M) Kuala Lumpur, Malaysia 
WORKING PAPER 2/2019

\section{A PROVINCIAL VIEW OF CONSUMPTION RISK SHARING: ASSET CLASSES AS SHOCK ABSORBERS}

\section{Victor Pontines*}

February 2019

*The South East Asian Central Banks (SEACEN) Research and Training Centre, Kuala Lumpur, Malaysia. Email: vpontines@seacen.org. The views expressed herein are solely those of the author and do not necessarily reflect the views of the SEACEN Centre and its member central banks. 


\begin{abstract}
Using a unique data on provincial net factor income flows disaggregated across the three asset classes of debt, equity and FDI reinvested earnings in Korea, we investigated how these asset channels impacted consumption risk sharing during the Global Financial Crisis and the European sovereign debt crisis. Adopting spatial panel methods, this study found that net receipts of debt, equity and FDI retained earnings have all contributed favorably to consumption risk sharing during these crises episodes, with FDI retained earnings robustly positive in its contribution in buffering shocks to consumption. We also found suggestive evidence that net equity receipts rather than net debt receipts contributed more to risk sharing during these episodes. Overall, our results indicate that different asset channels can provide the insurance needed to cushion the economy against adverse shocks.
\end{abstract}

JEL Classification: E21, E25, F21, R12

Keywords: $\quad$ Consumption Risk Sharing, Consumption Smoothing, Factor Income Flows, Spatial Panel

Disclaimer: This Working Paper should not be reported as representing the views of SEACEN or its member central banks/monetary authorities. The views expressed in this Working Paper are those of the author(s) and do not necessarily represent those of SEACEN or its member central banks/monetary authorities. 


\section{Table of Contents}

\section{Page}

Abstract iii

1. Introduction 1

2. Related Literature 3

3. Methodology 5

3.1 Consumption Risk-Sharing and the Contribution
of Net Factor Income Flows

3.2 Spatial Econometrics Interpretation of Consumption

Risk-Sharing and the Contribution of Net Factor Income Flows $\quad 7$

4. Empirical Results 9

4.1 Data 9

4.2 Consumption Smoothing and the Buffering Effects of
Various Net Factor Income Flows

5. Robustness Checks $\quad 12$

5.1 Inverse Squared Distance as Spatial Weights 12

$\begin{array}{ll}5.2 \text { Nearest Neighbors as Spatial Weights Matrices } & 13\end{array}$

$\begin{array}{ll}5.3 \text { Inverse Distance with Cut-offs as Spatial Weights Matrix } & 13\end{array}$

5.4 Different Time Periods 14

6. Conclusion 15

References 16

\section{List of Tables}

Table 1: Consumption Smoothing and the Buffering Effects of

Various Net Factor Income Flows: Baseline Results: Non-spatial Models 19

Table 2: LM Test Results for Choosing Between Spatial and Non-spatial Models 20

Table 3: Consumption Smoothing and the Buffering Effects of

Various Net Factor Income Flows: Main Results: Spatial Models

Table 4: Consumption Smoothing and the Buffering Effects of

Various Net Factor Income Flows: (Robustness Test Results of Spatial Models:

Inverse Squared Distance as Spatial Weight)

Table 5: Consumption Smoothing and the Buffering Effects of

Various Net Factor Income Flows: (Robustness Test Results of Spatial Models:

$\mathrm{K}$ Nearest Neighbor as Spatial Weight, $\mathrm{K}=2$ )

Table 6: Consumption Smoothing and the Buffering Effects of

Various Net Factor Income Flows: (Robustness Test Results of Spatial Models:

$\mathrm{K}$ Nearest Neighbor as Spatial Weight, $\mathrm{K}=3$ )

Table 7: Consumption Smoothing and the Buffering Effects of

Various Net Factor Income Flows: (Robustness Test Results of

Spatial Models: Inverse Distance with Cutoff < 250 KMs as Spatial Weight)

Table 8: Consumption Smoothing and the Buffering Effects of

Various Net Factor Income Flows: (Robustness Test Results of

Spatial Models: Inverse Distance with Cutoff < $350 \mathrm{KMs}$ as Spatial Weight)

Table 9: Consumption Smoothing and the Buffering Effects of

Various Net Factor Income Flows: (Robustness Test Results of

Spatial Models: Inverse Distance Spatial Weight, 2008-2012 Time Period)

Table 10: Consumption Smoothing and the Buffering Effects of

Various Net Factor Income Flows: (Robustness Test Results of

Spatial Models: Inverse Distance Spatial Weight, 2008-2011 Time Period) 


\title{
A PROVINCIAL VIEW OF CONSUMPTION RISK SHARING: ASSET CLASSES AS SHOCK ABSORBERS
}

\author{
By
}

\author{
Victor Pontines
}

\section{Introduction}

One of the key purported benefits of financial openness is that it offers residents of countries a larger pool of resources or assets that they can hold and diversify across asset classes. Because the revenue streams of these foreign assets are intimately linked to the volatility of output abroad, and thus, are less susceptible to domestic or local output shocks, residents are then provided the opportunity to "smooth out" changes in their consumption resulting from fluctuations in domestic output. We would then expect that greater financial openness offers more diversification opportunities for residents of countries and as such, lead to increased risk sharing.

Recent evidence has shown that greater financial openness leads to increased risk sharing only for developed economies (Artis and Hoffmann, 2008; Kose et al., 2009). ${ }^{1}$ As argued by Balli et al. (2013), however, these studies covered the period that relate to an era of financial upturn, especially for developed economies. For instance, Kose et al., (2009) referred to their sample period of 1987 to 2004 as the modern era of globalization. ${ }^{2}$ In that regard, we know little of how risk sharing performs during times of financial downturn or turmoil. One possible indication on how risk sharing can play out during a crisis is the observation that during the Global Financial Crisis and the European sovereign debt crisis, given that many countries were affected by these two crises, imply that the risk was shared, although the degree of risk sharing was imperfect as some countries were stricken more by the crises than others (Mendoza and Quadrini, 2010).

A later study by Balli et al., (2013) provided formal evidence on this issue. They examined how international risk sharing performed during the Global Financial Crisis for a set of advanced economies as well as looked at the relative contribution of the receipts and payments of net factor income flows (debt, equity and FDI reinvested earnings) on consumption risk sharing during this same period. They found that the financial crisis contributed only to a slight drop in consumption risk sharing in the countries comprising the European monetary union (EMU) and OECD countries. They also found that net receipts from

\footnotetext{
1 On the other hand, Bai and Zhang (2012) found little evidence of larger risk sharing among developed economies.

2 Artis and Hoffmann (2008) covered almost the same period as the Kose et al. (2009) study, which was from 1980 to 2000 .
} 
debt assets delivered better risk sharing than equity in the case of the OECD than in the European monetary union, while FDI supported consumption only in the OECD during the crisis.

Our paper contends with these same two issues on how consumption risk sharing fared during crises times, particularly, during the Global Financial Crisis and the European sovereign debt crisis, as well as the issue of the relative contribution of these three asset classes (debt, equity and FDI reinvested earnings) on consumption risk sharing during these crises. However, the paper's key contribution is on the examination of these issues from an intranational risk sharing perspective by utilizing data on provincial and metropolitan cities. Previous studies that investigated both issues from the angle of intra-national risk sharing, especially the second one, is non-existent. Earlier empirical research on intra-national consumption risk sharing has concentrated in general on the degree of consumption risk sharing using much earlier data for US states and Canadian provinces (Asdrubali et al., 1996; Crucini, 1999; Crucini and Hess, 2001; Athanasouli and van Wincoop, 2001).

The lack of publicly available regional data on net factor income flows disaggregated across the three asset classes of debt, equity and FDI reinvested earnings is the most likely reason for this dearth of studies, particularly, on the second issue. For this paper, in addition to publicly available data on regional consumption and GDP, we exploit available annual regional data on net factor income flows disaggregated across the three asset classes in the case of Korea. ${ }^{3,4}$ Specifically, the data is available for the entire 16 Korean provinces and metropolitan cities (henceforth provinces). Korea offers as an interesting case. After being one of the East Asian country hardest hit by the 1997 Asian financial crisis, Korea did not reverse course and continue on a path of a gradual and systematic liberalization of capital flows initially announced in 1998 (IMF, 2012). From 2005 to 2007, locally owned Korean banks and the branches of foreign banks in Korea experienced rapid inflows in the form of short-term liabilities. The country was at the sharp end of the financial turmoil after the failure of Lehman Brothers in September 2008 and again during the European sovereign debt crisis when it experienced substantial capital outflows (Bruno and Shin, 2014; BOK, 2010, 2012, 2013, 2014, 2015).

One other innovation that we introduce in this study is that we employ the technique of spatial econometrics to analyze the issues with direct relevance to consumption risk sharing. To the best of our knowledge, while this technique has been applied to various economics and financial issues, this is the first time that this method is being applied for the issue of

\footnotetext{
${ }^{3}$ In this study, Korea refers to the Republic of Korea.

${ }^{4}$ The available data is basically the individual region's net factor income, that is, receipts by the region from non-residents located abroad less payments made by the same region to non-residents located abroad, with respect to the three respective factor or asset classes.
} 
consumption risk sharing. ${ }^{5}$ It is becoming a standard nowadays that when dealing with regional or provincial data, a spatial approach needs to be considered. Perhaps, the most important argument for considering a spatial approach is that the independence assumption between observations is no longer valid. Provinces or regions that are located much closer to each other within a nation are more related than distant ones such that externalities or neighborhood effects need to be considered using spatial variables such as distance. Conventional regression models assume that observations are independent of one another and as such, fail to take account of this dependence between observations. This can lead to estimation results that are biased.

The main findings of this paper are as follows: first, similar to earlier estimates of intranational consumption risk sharing in other advanced countries, the degree of consumption risk sharing in Korea is also imperfect with estimates that range from 47 per cent to 61 per cent, although relatively lower compared to earlier estimates obtained for US states and Canadian provinces. Second, net receipts of debt, equity and FDI retained earnings have all contributed favorably to consumption risk sharing during the crises with FDI retained earnings robustly positive in contributing to consumption risk sharing during this turbulent period. Third, we also obtain evidence in one of our robustness checks that closer to the period of the intense volatility in international financial markets that occurred during the period, not only the overall degree of consumption risk sharing increased, but the net contributions of the three asset classes to consumption smoothing in Korea likewise increased. Related to this latter finding, there is evidence to suggest that between net equity and net debt receipts, it was the former not the latter that buffered more the shocks to consumption.

The rest of the paper is organized as follows. The next section briefly provides a review of the related literature. Section 3 discusses the models and the main technique employed in this study. Section 4 discusses the data and the empirical results. The last section concludes.

\section{Related Literature}

The literature on consumption risk sharing is voluminous. Because of this and in the interest of conciseness, our aim in this sub-section is to summarize the findings of studies that have direct relevance to our study. Our study connects two separate strands of literature within the overarching topic of consumption risk sharing. The first strand of literature assesses the degree of risk sharing within a country using state or provincial level data, with studies mostly focused on US states and Canadian provinces. This strand of literature is generally based on regressions of consumption growth and some measure of income growth, and the general finding from this literature is that consumption risk sharing is less than perfect. For instance, in an influential study, Asdrubali et al., (1996) estimated the amount of consumption risk

\footnotetext{
${ }^{5}$ For instance, the technique has been applied to analyze sovereign risks in emerging markets (Kişla and Önder, 2018), house price dynamics (Cohen et al., 2016), apartment transaction prices during boom and bust (Hyun and Milcheva, 2018), to mention a few.
} 
sharing in the US and found that it is far from perfect. Based on the decomposition that they developed which identified distinct channels of risk sharing among US states, they found that for the period of 1963-1990, 75 per cent of shocks are shared among US states.

Using a revision to the method of Asdrubali et al., (1996), Mélitz and Zumer (1999, 2002) and Asdrubali and Kim (2004) found similar results for US states. The related studies of Crucini (1999) and Crucini and Hess (2000) assumed that the permanent income hypothesis hold and used as their measure of income growth, time series of innovations to permanent income for each region. Both studies found that for the period of 1973 to 1991(Crucini, 1999) and 1971 to 1991 (Crucini and Hess, 2000), the degree of consumption risk sharing tends toward 90 per cent, suggesting quite a high degree of consumption risk sharing.

The second strand of literature are studies that examine the impact of factor income flows on the extent of international consumption risk sharing among a group of countries. Sørensen et al. (2007) first documented the effect of foreign asset and liability holdings on consumption risk sharing in the OECD and European monetary union (EMU) over the period 1993-2003. They found that larger holdings of equity and FDI components of foreign assets are associated with more international risk sharing than holdings of debt. With regard to foreign liabilities, only FDI liabilities was found to have a significant role on consumption risk sharing. Demyanyk et al., (2008) employed a similar econometric specification as Sørensen et al. (2007) using data for EMU and EU countries over the period 1996-2006 and found that only the debt holdings of foreign assets have a significant role on consumption risk sharing. Kose et al., (2009) using annual data over the period 1960-2004 for 69 countries comprising a mix of developed, developing and emerging market economies found that only developed countries had attained better risk sharing outcomes during the period of globalization, whereas, developing countries had not benefited.

Employing a similar econometric specification as Sørensen et al. (2007) and using data over the period 1970-2005 for 35 developed and emerging market economies, Bracke and Schmitz (2011) also found the same results as Kose et al., (2009). They further showed, nonetheless, that when a certain measure of net capital gains behaved in a countercyclical way, that is, positive (negative) when the domestic economy is growing more slowly (rapidly) than the rest of the world, there is improved consumption risk sharing. However, this finding also only holds for developed economies. Balli et al., (2012) also considered a certain measure of capital gains using data over the period 1992-2007 for EMU, EU and OECD countries. They found that risk sharing from capital gains is higher than risk sharing from factor income flows for EU and OECD countries, whereas, risk sharing from factor income flows is higher for eurozone countries. Much closer to our work is the study by Balli et al., (2013), using data over the period 1999-2009 for EMU and OECD countries, which found that the Global financial crisis contributed only to a slight drop in consumption risk sharing in the countries of the EMU and OECD. They also found that net receipts from debt assets delivered better consumption risk sharing than equity in the case of the OECD than in the EMU, while FDI supported consumption only in the OECD during the crisis. 


\section{Methodology}

\subsection{Consumption Risk-Sharing and the Contribution of Net Factor Income Flows}

In this sub-section we first layout the basic non-spatial models as the starting point in our eventual incorporation of spatial interaction effects to these models that quantify the impact of net factor income flows on consumption risk sharing. We begin with the basic empirical specification of Sørensen et al. (2007) augmented by two-way fixed effects and is given by:

$$
\Delta \log (\dddot{C})_{j t}=\beta_{U} \Delta \log (R G \dddot{D} P p c)_{j t}+\mu_{j}+v_{t}+\varepsilon_{i t}
$$

where $\Delta \log (\dddot{C})_{j t}=\Delta \log (C)_{j t}-\Delta \log (C)_{t}$ and $\Delta \log (R G \dddot{D P} p c)_{j t}=\Delta \log (R G D P p c)_{j t}-\Delta$ $\log (R G D P p c)_{t .}$ In the present context, in contrast to Sørensen et al. (2007), j refers to the entire provinces comprising Korea as opposed to a group of OECD countries considered in the Sørensen et al. (2007) study, while $t$ refers to the time-period. In this regard, $C_{j t}$ and $R G D P p c_{j t}$ are province js year $t$ real per capita consumption and real GDP per capita, respectively, and, $C_{t}$ and $R G D P p c_{t}$ are the national real per capita consumption and real GDP per capita, respectively, in year $t . \Delta \log (\dddot{C})_{j t}$ is then the growth of province $j$ 's idiosyncratic real per capita consumption (i.e., the difference between the growth of province j's real per capita consumption to the growth in national real per capita consumption), while $\Delta \log (R G \dddot{D P} P p c)_{j t}$ is province j's idiosyncratic real GDP per capita growth (i.e., the difference between the growth of province is real GDP per capita to the growth in national real GDP per capita). The parameter $\beta \cup$ measures the average comovement of the provinces' idiosyncratic real per capita consumption growth with their idiosyncratic real GDP per capita growth. Finally, $\mu_{j}$ represents the jth province fixed effects, $v_{t}$ represents the th year of time-period fixed effects, and $\varepsilon_{i t}$ is the error term.

The basic argument of the risk-sharing literature is that the fluctuations in the pooled or aggregate real consumption of the entire country (i.e., the group) cannot be smoothed or eliminated by the sharing of risk. Because of this, as can be observed from equation (1) above, to measure the amount of risk that is shared among the provinces, the fluctuations in the pooled or aggregate component must be removed from the provincial-level fluctuations to isolate the smoothable fluctuations in real per capita consumption (Sorensen and Yosha, 2000). Under perfect risk sharing, the left-hand side of equation (1) will be zero implying that $\beta_{u}$ will be zero. The smaller the comovement between idiosyncratic real per capita consumption growth and idiosyncratic real GDP per capita growth, the higher the amount of consumption is buffered against GDP fluctuations, the smaller the estimated value of the parameter, $\beta \cup$. The metric, $1-\beta \cup$ measures the amount of consumption risk-sharing which can take the value of 1 if risk-sharing is perfect and the value of 0 if idiosyncratic real per capita consumption growth moves one-to-one with idiosyncratic real GDP per capita growth. 
From equation (1) above, we move next to the basic non-spatial empirical specification of the impact of different asset classes (bonds, equity, FDI) on consumption risk-sharing achieved through net factor income flows. In Balli et al. (2013), they first employed the national income accounts formulation of the net factor income (NFI) expressed as follows:

$$
\mathrm{NFI} \approx N e t \text { Interest_Receipts }+ \text { Net_Dividend_Receipts }+ \text { Net_Receipts_FDI_Re_E }
$$

That is, equation (2) is simply the decomposition of the NFI into the net receipts from the various asset classes in the form of net interest receipts (Net_Interest_Receipts) (i.e., debt), net dividend receipts (Net_Dividend_Receipts) (i.e., equity), and net receipts on FDI reinvested earnings (Net_Receipts_FDI_Re_E) (i.e., FDI reinvested earnings). ${ }^{6}$ From this decomposition of the NFI, Balli et al. (2013) examined the influence of net factor income flows on consumption risk-sharing by extending the earlier empirical specification of Sorensen et al. (2007) given in equation (1) above as follows:

$$
\Delta \log (C \stackrel{\cdots}{-} X)_{j t}=\beta_{C}^{+} \Delta \log (R G \dddot{D} P p c)_{j t}+\mu_{j}+v_{t}+\varepsilon_{i t}
$$

where $\Delta \log (R G \dddot{D P P} p)_{j t}, \mu_{j}, v_{t}$, and $\varepsilon_{i t}$ are as defined earlier, while $X$ corresponds either to the net receipts of equity, bond, and FDI reinvested earnings. More precisely, and for completeness given the net receipts from these three asset classes, equation (3) can be reexpressed as follows:

$$
\begin{aligned}
& \Delta \log \left(C_{-} N e t \_D \imath v i d e n d \_R e c e \imath p t s\right)_{j t}=\beta_{C}^{d i v+} \Delta \log (R G \dddot{D P} P c)_{j t}+\mu_{j}+v_{\mathrm{t}}+\varepsilon_{i t} \\
& \Delta \log \left(C_{-} \text {Net_Interest_Recelpts }\right)_{j t}=\beta_{C}^{\text {int } t+} \Delta \log (R G \dddot{D P} p c)_{j t}+\mu_{j}+v_{\mathrm{t}}+\varepsilon_{i t} \\
& \Delta \log \left(C_{-} \text {Net_Receipts_FDI_Re_E }\right)_{j t}=\beta_{C}^{F D I+} \Delta \log (R G \dddot{D P p} P)_{j t}+\mu_{j}+v_{t}+\varepsilon_{i t}
\end{aligned}
$$

where $\quad \Delta \log \left(C_{-} \text {Net_Dıvıdend_Receipts }\right)_{j t}=\Delta \log (C-\quad \text { Net_Dividend_Receipts })_{j t} \quad$ $\Delta \log (C-N e t \text { Dividend_Receipts })_{t}$ is province js real per capita consumption less real per capita net dividend receipts minus the national counterpart. $\Delta \log \left(C_{-} N_{\text {Net_Interest_Recelpts }}\right)_{j t}=$ $\Delta \log (C-N e t \text { Interest_Receipts })_{j t}-\Delta \log (C-N e t \text { Interest_Receipts })_{t}$ is province js real per capita consumption less real per capita net interest receipts minus the national counterpart. And, $\quad \Delta \log \left(C_{-} N e t_{-} R e c e i p t s_{-} F D I_{-} R e_{-} E\right)_{j t}=\Delta \log \left(C-N e t_{-} R e c e i p t s_{-} F D I_{-} R e_{-} E\right)_{j t} \quad-$

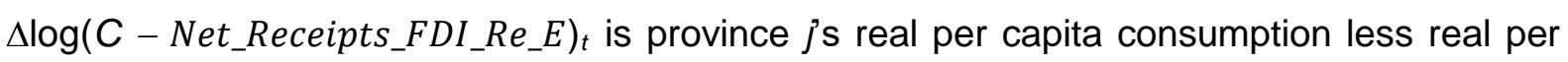
capita net receipts of FDI reinvested earnings minus the national counterpart.

Because each of the net receipts from the three asset classes are deducted from consumption to form the modified dependent variables in equations ( $3 a)$ to (3c), which is then

\footnotetext{
${ }^{6}$ Balli et al. (2013) also considered separately, the gross receipts and gross payments in each of the three asset classes for a group of OECD countries. In this study, however, we only use the net receipts (difference between gross receipts and gross payments) in each of the three asset classes since these are the only available data at the provincial level for Korea.
} 
regressed with the idiosyncratic real GDP per capita growth, the parameters, $\beta_{C}^{\text {div }+}, \beta_{C}^{\text {int+ }}$ and $\beta_{C}^{F D I+}$ can each be interpreted as indicating the presence, if any, of a buffering effect of the pertinent net factor income flows on consumption from fluctuations in idiosyncratic real GDP per capita growth. More precisely, according to Balli et al. (2013), a larger estimate of these parameters in equations (3a) to (3c) relative to the estimate of the parameter $\beta_{u}$ in equation (1) indicate an increase in consumption risk-sharing or that the net receipts from the pertinent asset class contribute in buffering shocks to consumption.

\subsection{Spatial Econometrics Interpretation of Consumption Risk-Sharing and the Contribution of Net Factor Income Flows}

The main advantage of working with spatial panels is that one can control for spatialspecific effects. Spatial units of observations such as regions, provinces and cities are likely to differ in their background variables, which can affect real per capita consumption growth (Elhorst, 2017). For instance, the extent of one province to trade financial assets with nonresidents from other countries can depend on whether the province is located far away or close to the financial hubs of the nation. In this sub-section, we then present the estimating equations that incorporate spatial interaction effects to our basic empirical models that quantify the impact of net factor income flows on consumption risk sharing. For instance, we can expand equation (1) by augmenting it by two spatial terms, a spatial lagged dependent variable $\left(\sum_{j=1}^{n} W_{i j}\left(\Delta \log (\dddot{C})_{j t}\right)\right.$ and a spatial correlated error term $\left(\sum_{j=1}^{n} W_{r, j} \varepsilon_{i t}\right)$ which can be expressed as follows:

$$
\Delta \log (\dddot{C})_{j t}=\lambda \times \sum_{j=1}^{n} W_{i j}\left(\Delta \log (\dddot{C})_{j t}\right)+\beta_{U}^{S} \Delta \log (R G \dddot{D P} P p c)_{j t}+\mu_{j}+v_{\mathrm{t}}+\rho \times \sum_{j=1}^{n} W_{r, j} \varepsilon_{i t}+
$$

We can accord to the parameter, $\beta_{U}^{S}$, a similar interpretation just as we earlier attached to the parameter $\beta_{\cup}$ in equation (1). ${ }^{7}$ This basically measures the average comovement of the provinces' idiosyncratic real per capita consumption growth with their idiosyncratic real GDP per capita growth and as such, $1-\beta_{U}^{S}$, measures the level of consumption risk sharing among the provinces. In the spatial econometrics literature, having both a spatial lagged dependent variable and a spatial correlated error term such as equation (4) is referred to as a spatial autoregressive combined (SAC) model. In that regard and in an equivalent manner, we can also expand equations (3a) to (3c) to a SAC model by the appropriate inclusion of spatial lagged dependent variable terms and spatial correlated error terms:

\footnotetext{
${ }^{7}$ To distinguish our spatial parameters to the non-spatial ones, we include the capital letter $S$ as superscript when referring to the spatial parameters.
} 
$\Delta \log \left(C_{-} N e t \_D \imath v \imath \dddot{2} \text { end_Recelpts }\right)_{j t}=\lambda \times \sum_{j=1}^{n} W_{i j}\left(\Delta \log \left(C_{-} N \text { Net_Dlvıdend_Recelpts }\right)_{j t}\right) \quad+$

$$
\beta_{C}^{\text {Sdiv }+} \Delta \log (R G \dddot{D P} P c) j t+\mu_{j}+v_{\mathrm{t}}+\rho \times \sum_{j=1}^{n} W_{r, j} \varepsilon_{i t}+\varepsilon_{i t}+\varphi_{i}
$$

$\Delta \log \left(C_{-} N e t_{-} \text {Interest_Recelpts }\right)_{j t}=\lambda \times \sum_{j=1}^{n} W_{i j}\left(\Delta \log \left(C_{-} N \text { Net_Interest_Recelpts }\right)_{j t}\right)$

$$
+\beta_{C}^{\text {Sint }+} \Delta \log (R G \dddot{D P} P P C)_{j t}+\mu_{j}+v_{\mathrm{t}}+\rho \times \sum_{j=1}^{n} W_{r, j} \varepsilon_{i t}+\varepsilon_{i t}+\varphi_{\mathrm{i}}
$$

$\Delta \log \left(C_{-} N e t_{-} R e c e i p t s_{-} F D I_{-} R e_{-} E\right)_{j t}=\lambda \times \sum_{j=1}^{n} W_{i j}\left(\Delta \log \left(C_{-} N e t_{-} R e c e i \dddot{p t} s_{-} F D I_{-} R e_{-} E\right)_{j t}\right)+$

$$
\beta_{C}^{S F D I+} \Delta \log (R G \ddot{D P} P c)_{j t}+\mu_{j}+v_{\mathrm{t}}+\rho \times \sum_{j=1}^{n} W_{r, j} \varepsilon_{i t}+\varepsilon_{i t}+\varphi_{i}
$$

where $W_{i j}$ is the row-normalized spatial weights matrix that contains the inverse distances (in kilometres) between the capitals or central districts of each pair of provinces in Korea. This allows us to distinguish between neighboring and distant provinces by decreasing the relative weights of the farther ones. The idea is that spatial dependence is expected to diminish with increasing distance. ${ }^{8}$ Nonetheless, because an important consideration in spatial econometrics is how to specify the spatial weighting matrix (LeSage and Fischer, 2008), in the robustness checks of our estimation results, we will consider different alternative matrices as spatial weights. Also, in equations (5a) to (5c), $\varphi_{i}$ is a fixed error term which does not vary over time, while the rest of the variables are as defined earlier.

The parameters $\beta_{C}^{\text {Sdiv }+}, \beta_{C}^{\text {Sint }+}$ and $\beta_{C}^{S F D I+}$ can also be interpreted similar to the parameters, $\beta_{C}^{d i v+}, \beta_{C}^{i n t+}$ and $\beta_{C}^{F D I+}$ in equations (3a) to (3c). These parameters indicate the presence, if any, of a buffering effect of net factor income flows on consumption growth from fluctuations in idiosyncratic real GDP per capita growth. A larger estimate of these parameters relative to the estimate of the parameter $\beta_{U}^{S}$ (equation 4 ) indicate an increase in consumption risk-sharing or that the net receipts from the pertinent asset class contribute to buffering shocks to consumption. Also from equations (5a) to (5c) above, $\lambda$ is the coefficient of the spatial lagged dependent variable which is the measure of association among the spatial units, while, $\rho$ denotes the coefficient of the spatial correlated error term which indicates the spatial association among the regression residuals. These two coefficients must follow a stationarity requirement which states that: $1 / \omega_{\min }<\lambda<1 / \omega_{\max }$ and $1 / \omega_{\min }<\rho<1 / \omega_{\max }$, where $\omega_{\min }$ and $\omega_{\max }$ denote the smallest (i.e., most negative) and largest characteristic roots of the spatial weights matrix, $W_{i j}$ (Elhorst, 2010). Finally, nested in a SAC model are two alternative specifications of spatial models. Specifically, if $\lambda=0$ and $\rho \neq 0$, equations (4) and (5a) to (5c) are represented by a spatial error model (SEM). If, on the other hand, $\lambda \neq 0$ and $\rho=0$, a spatial lagged dependent model (SLM) represents equations (4) and (5a) to (5c). Thus, the SAC models presented above assume that $\lambda \neq 0$ and $\rho \neq 0$.

\footnotetext{
${ }^{8}$ This follows from Tobler's first law of geography that, "everything is related to everything else, but near things are more related than distant things."
} 


\section{Empirical Results}

\subsection{Data}

We use a dataset consisting of a panel of 16 provinces and metropolitan cities for Korea for which annual data are available for the variables that we utilized in this study. Our period of study is from 2008 to 2015, which surround the years of the Global Financial Crisis and the European sovereign debt crisis. All of the variables were measured in real per capita terms and were constructed by dividing real values by the population series. The variables utilized in this study such as real GDP (in 2010 prices), real final consumption (also in 2010 prices and defined as the sum of household consumption and government consumption), GDP deflators, net receipts of the factor income flows (i.e., net dividend receipts, net interest receipts and net FDI retained earnings) ${ }^{9}$ and population were obtained from the Korea Statistical Information Service (http://kosis.kr/eng/). The net receipts of the net factor flows were first converted to real terms using the available GDP deflators and subsequent real per capita figures were obtained by dividing them by the population. For our period of study, national and provincial population data are available for the years 2005, 2010 and 2015.

\subsection{Consumption Smoothing and the Buffering Effects of Various Net Factor Income Flows}

\section{A. Baseline Case}

Table 1 shows our baseline results using fixed effects estimation. The fixed effect is more suitable for our study because in a random-effect, apart from its strong assumption that there is no correlation between our explanatory variable and the cross-sectional fixed effect, it is only appropriate when the samples are randomly drawn from the population. However, in view that we are examining all provinces in Korea, the fixed-effect is more suitable for our purpose.

Table 1 has four columns, with column (1) reporting the estimation results of the nonspatial fixed-effect model corresponding to equation (1), while the estimation results corresponding to equations (3a), (3b) and (3c) are shown in columns (2) to (4) in that particular order. The first observation we can make is that about 52 per cent (column 1) of idiosyncratic consumption growth remains unsmoothed such that there is an almost equivalent level of consumption risk sharing that takes place up to around 48 per cent. Although this level of risk sharing is imperfect, these estimates are strongly statistically significant. The contribution to consumption risk-sharing of the net receipts from the three asset classes, i.e., equity (column (2)), bonds (column (3)) and FDI retained earnings (column (4)) can be examined by

\footnotetext{
${ }^{9}$ Available data is only in net receipts, which is basically the difference between the receipts from nonresidents located abroad to payments made to non-residents located abroad for that particular factor or asset class.
} 
comparing the reported results in these three columns to column (1). Our baseline results suggest that because our estimate of the parameters, $\beta_{C}^{\text {div+ }}$ (56 per cent), $\beta_{C}^{\text {int+ }}$ (61 per cent) and $\beta_{C}^{F D I+}$ (63 per cent) were all higher relative to our estimate of $\beta_{\cup}$ (52 per cent), all three asset classes contributed favorably to buffering shocks to consumption with FDI retained earnings contributing the most (at 11 percent $=63$ per cent -52 per cent) followed by debt (at 9 percent) and then by equity (4 percent). These estimates are again strongly statistically significant.

\section{B. Main Results}

If there is spatial dependence within our panel data, however, the estimated coefficients from our baseline panel fixed effects are biased upwards (Elhorst, 2017). To test for the presence of spatial dependence, we follow Anselin, Le Gallo and Jayet (2008) and conduct the Lagrange Multiplier (LM) tests for a spatial lagged dependent variable (i.e., LM spatial lag) and a spatial correlated error term (i.e., LM spatial error). The LM test is based on the residuals of an OLS regression. If the non-spatial model is rejected in favor of the spatial lag dependent variable model, the spatial correlated error model, or in favor of both models, then models which incorporates such spatial interaction effects are appropriate to use.

Table 2 presents the classic LM tests results and their robust counterparts for the different model specifications. The table contains four panels: Panels A, B, C and D present the LM test results for $\Delta \log (\dddot{C})_{j t,} \quad \Delta \quad \log \left(C_{-} \text {Net_Dıvıdend_Receipts }\right)_{j t,}, \quad \Delta$ $\log \left(C_{-} \text {Net_Interëst_Receipts }\right)_{j t}, \quad$ and $\quad \Delta \quad \log \left(C_{-} N e t_{-} \text {Receipts_FDI_Re_E }\right)_{j t} \quad$ equations, respectively. According to these LM tests, the hypothesis of no spatial lag dependent variable and the hypothesis of no spatial correlated error term were not rejected for all equations with province fixed effects as well as both hypotheses not rejected for all equations with time-period fixed effects. However, both hypotheses were rejected (either at the 7 per cent or 5 per cent significance level) for all equations with province and time-period fixed effects using the classic LM tests (except for the $\Delta \log \left(C_{-} \text {Net_Interest_Recelpts) }\right)_{j t}$ which also rejects the hypothesis of no spatial lag dependent variable using the robust LM test). Overall, these results suggest that a spatial model with two-way fixed effects (province and time-period fixed effects) rather than a non-spatial model is the appropriate specification to use.

Table 3 reports our main results of our spatial two-way fixed-effect models corresponding to equations (4) and (5a) to (5c). Specifically, column (1) corresponds to the estimation of equation (4), while columns (2), (3) and (4) correspond to the estimation of equations (5a), (5b) and (5c), respectively. Each column of this table contains three panels of estimation results: the top panel (labeled (i) SAC) reports the fixed-effect estimation results from the SAC model, and the middle (labeled (ii) SLM) and bottom panels (labeled (iii) SEM) report the fixed-effect estimation results from the SLM and SEM models, respectively. We begin our analysis with the results reported in column (1) of Table 3. We find that in the SAC model about 52 per cent of idiosyncratic consumption growth remains unsmoothed such that 
there is an almost equivalent level of consumption risk sharing that takes place of around 48 per cent. In addition to an imperfect risk sharing albeit with strong statistical significance, these estimates are identical to our earlier baseline estimates reported in Table 1. The two spatial coefficients, $\rho$ and $\lambda$, fulfill the stationarity requirements, however, as both coefficients are statistically insignificant. Similar observations can also be made regarding the estimates of these two spatial coefficients from the other SAC models reported in the rest of the columns in Table 3.

Recall that the SAC model nests two alternative spatial panel models, i.e., the SLM model (which restricts $\rho$ equal to zero) and the SEM model (which restricts $\lambda$ equal to zero). The results reported in column (1) of Table 3 for these two alternative spatial panel models reveal that the level of unsmoothed shocks to idiosyncratic consumption growth according to the SEM model is also at around 52 per cent, whereas according to the SLM model, it is slightly lower at around 49.5 per cent (consumption risk sharing is then at about 50.5 per cent). Both these estimates of consumption risk sharing are relatively lower compared to estimates obtained for US states and Canadian provinces using much earlier data. In the case of US states, for instance, the estimates ranged from 75 per cent (Asdrubali et al., 1996) to 94 per cent (Crucini, 1999), whereas for Canadian provinces, it is between 88 per cent to 90 per cent (Crucini, 1999; Crucini and Hess, 2000). In each of these models, the spatial coefficients, $\lambda$ in the SLM model and $\rho$ in the SEM model were also found to fulfill the stationarity requirement. However, in contrast to the estimates of these coefficients in the SAC model, their respective estimates in the SLM and SEM models were found to be significant. In view of these results, our preference from this point is to focus our analysis on the estimated results obtained from our SLM and SEM models.

Next, we turn our attention to the next important question in this study of how our net receipts from the three asset classes contributed in buffering shocks to consumption. Our answer to this question is provided in the remainder of the columns (columns (2) to (4)) in Table 3. The first notable observation we can gather from these set of estimation results is that all the respective estimates of $\lambda$ and $\rho$ in the SLM and SEM models fulfill the stationarity requirement ${ }^{10}$ and were found to be statistically significant. The second notable observation is that net receipts from the three asset classes contributed positively to consumption risk sharing. Again, recall that in order to support this finding, our estimate of the parameters $\beta_{C}^{\text {Sdiv }}, \beta_{C}^{\text {Sint }+}$ and $\beta_{C}^{S F D I+}$ should be larger than our estimate of the parameter $\beta_{U}^{S}$. Indeed, our respective estimates of these parameters confirm this finding. Compared to our estimates of $\beta_{U}^{S}$ which are 49.5 per cent in SLM and 52 per cent in SEM (column 1), the estimates of $\beta_{C}^{\text {Sdiv }}$ are reported in column (2) at 51.5 percent in SLM and 53 per cent in SEM, $\beta_{C}^{\text {Sint }{ }^{+} \text {at }} 54$ per cent in SLM and 55 per cent in SEM (column (3)), and the estimates of $\beta_{C}^{S F D I+}$ reported in column (4) at 57 per cent in SLM and 59 per cent in SEM. Based on these reported estimates,

\footnotetext{
10 The values of the stationarity bounds, $1 / \omega_{\min }$ and $1 / \omega_{\max }$ are reported at the bottom of the notes section of each table.
} 
our next notable finding is that similar to our results in the baseline, in the non-spatial case (again refer to Table 1), FDI retained earnings contributed the most (7.5 per cent in SLM and 7 per cent in SEM), followed by debt (4.5 per cent in SLM and 3 per cent in SEM) and then by equity (2 percent in SLM and 1 per cent in SEM). In contrast to our baseline estimates, however, the contribution of these three asset classes in buffering shocks to consumption are relatively smaller. This is because our estimates of the spatial parameters $\beta_{C}^{\text {Sdiv }+}, \beta_{C}^{\operatorname{Sint+}}$ and $\beta_{C}^{S F D I+}$ are relatively smaller compared to the estimates of the parameters $\beta_{C}^{\text {div }}, \beta_{C}^{\text {int+ }}$ and $\beta_{C}^{F D I+}$ in the non-spatial, baseline case. We can then argue that this latter outcome arises because of the upward bias inherent in our estimates of these coefficients in the baseline case.

\section{Robustness Checks}

This section examines the robustness of our main results along various dimensions: using different alternative distance matrices as spatial weights, including, the inverse squared distance, the two $(k=2)$ and three nearest neighbors $(k=3)$ of the respective provinces, ${ }^{11}$ the inverse distance with cut-offs ( $250 \mathrm{kms}$. and $350 \mathrm{kms}$.) as well as considering different periods to account for the crises years, i.e., 2008-2012 and 2008-2011.

\subsection{Inverse Squared Distance as Spatial Weights}

In this sub-section, we will examine the sensitivity of our main findings by considering this time the inverse squared distances (assumes that neighboring relations are nonlinear and decline quicker the farther the distance) between the capitals or central districts of each pair of provinces in Korea as an alternative spatial weight in the estimation of our spatial models corresponding to equations (4) and (5a) to (5c). Table 4 presents the estimation results. While all of our estimates of the spatial coefficients, $\lambda$ and $\rho$ in the SLM and SEM models fulfill the stationarity requirement, some are found to be insignificant. ${ }^{12}$ More importantly, however, the consumption risk sharing that takes place is about 50 per cent and 49 per cent in the SLM and SEM models, respectively. These estimates are quite close to the level of risk sharing that we found in the main results and these estimates are strongly statistically significant.

How about the contribution of the three asset classes in buffering shocks to consumption? Again, FDI retained earnings contributed the most (10 per cent in SLM and 10 per cent in SEM), followed by debt (7 per cent in SLM and 7 per cent in SEM) and then by equity (4 per cent in SLM and 4 per cent in SEM). These reported estimates in Table 4 are also quite close to the net contributions of the three asset classes to risk sharing found in the main results. Furthermore, we can again observe that these same reported contributions of the three asset classes in buffering shocks to consumption are relatively smaller compared to

\footnotetext{
${ }^{11} \mathrm{k}$ is usually denoted in the spatial econometrics literature as the number of nearest neighbors.

12 These are the cases of the estimates in the SLM and SEM models in column (2) and the SEM models in columns (3) and (4).
} 
the baseline results (except for equity for which the net contribution is identical at 4 per cent in the main and baseline cases). This again points to the upward bias in the estimates of the coefficients in the baseline case.

\subsection{Nearest Neighbors as Spatial Weights Matrices}

The next alternative spatial weights matrix that we will consider in the estimation of our spatial models and test the robustness of our main results is to use the two and three closest neighbors of each of the provinces. The idea is that after obtaining the distances between the capitals or central districts of each pair of provinces in Korea, we rank them and then consider as neighbors the two or three closest ones to a particular province. Table 5 presents the results for the spatial weights matrix constructed using the two closest neighbors, while Table 6 is for the spatial weights matrix constructed using the three closest neighbors. We find the results of this sensitivity test to be qualitatively identical with the main results. First, the consumption risk sharing that takes place (about 49 per cent in the SLM model and around 47 per cent in the SEM model in both tables) is almost of the same magnitude and statistical significance as the level of risk sharing obtained in the main results.

Second, FDI retained earnings again contributed the most (7 per cent (SLM and SEM)) in Table 5 and 8 per cent (SLM and SEM) in Table 6) in terms of the contribution of the three asset classes in buffering shocks to consumption. Next is also debt ( 5 per cent (SLM and SEM)) in both Tables 5 and 6 ) and followed by equity (1.5 per cent in SLM and 2 per cent in SEM) in Table 5, while none (SLM and SEM) in Table 6). Third, with the exception of the net contribution of equity in the SLM and SEM models in Table 6, these reported estimates are just about of the same level of contributions to risk-sharing that we found for these three asset classes in the main results. Likewise, compared to the baseline case, these same reported estimates of the asset classes' contributions in buffering shocks to consumption are smaller relative to the former, which again reinforces the observation of the upward bias inherent in our baseline results.

\subsection{Inverse Distance with Cut-offs as Spatial Weights Matrix}

The last alternative spatial weights matrix that we will consider to check the sensitivity of our main results is to use the inverse distance with cut-offs of $250 \mathrm{kms}$. and $350 \mathrm{kms}$., respectively. The idea is that we only compute the inverse distances between the capitals or central districts of a particular pair of provinces if the distance between them is less than the maximum distance of $250 \mathrm{kms}$. and $350 \mathrm{kms}$., respectively, whereas it is accorded a weight of zero if the distance is farther than these cut-offs. Table 7 presents the results for the spatial weights matrix constructed using the inverse distance with cut-off of $250 \mathrm{kms}$., while Table 8 presents the results with cut-off of $350 \mathrm{kms}$. 
The results presented in these two tables suggest that again, our main results hold, i.e., one, the consumption risk sharing that takes place is almost of the same magnitude and statistical significance in the main results and two, FDI retained earnings contributed the most, followed by debt, and last is equity in terms of the contributions of these asset classes to risksharing. Three, the level of contributions to risk-sharing by these three asset classes are comparable to those found in the main results. Finally, also similar to the main results, when compared to the baseline case, the estimates of the contributions of the asset classes in buffering shocks to consumption are relatively smaller, which we again interpret as revealing the upward bias in our baseline results. Taken together, these results using different alternative distance matrices as spatial weights lend further credence to the main results of this paper. We now turn to the final set of robustness checks that we conducted in this study.

\subsection{Different Time Periods}

Until this point, all of our reported estimation results are for the period of 2008 to 2015, which surround the years of the Global Financial Crisis and the European sovereign debt crisis. Specifically, the collapse of Lehman Brothers in September 2008 explains the choice of 2008 as the start of the sample period, while the reason for ending the sample period in 2015 has to do with the fact that the quantitative easing program in the eurozone started then. However, pinpointing exactly as to when the eurozone crisis ended can still be debatable. In this sub-section, as our final set of robustness tests, we estimate our spatial panel models for two different periods. One is for a shorter sample period of 2008 to 2012, the other for an even shorter period of 2008 to 2011. In the former, 2012 was also the year that ECB President Mario Draghi made the quite famous remark, "whatever it takes" to dramatically account for the dire situation that the eurozone was facing at that time. ${ }^{13}$ With regard to the latter even shorter period, as the Greek financial crisis was unfolding, 2011 was the year that European leaders for the first time publicly declared that Greece's departure from the eurozone was a possibility. ${ }^{14}$ It was also in this year that Portugal requested for a bailout, which was quickly approved by the EU. ${ }^{15}$

Table 9 presents the results for the period of 2008 to 2012, while Table 10 presents the estimation results for the 2008 to 2011 period. In both of these relatively shorter sample periods, we find the following: ${ }^{16}$ First, the level of consumption risk-sharing are relatively larger compared to the main results. Second, with the lone exception of debt in the SEM model in Table 10, all asset classes again contributed positively in buffering shocks to consumption during these two periods. Third, this time, however, equity contributed more in buffering shocks to consumption, followed by FDI retained earnings, and then by debt. Fourth, the

\footnotetext{
13 The remark was made by Mario Draghi in a speech in London on July 26, 2012.

14 The public declaration was made in a G20 summit held in Cannes, France on November 3, 2011.

${ }^{15}$ Portugal requested for a bailout package on April 6, 2011 and was officially approved on May 16, 2011.

${ }^{16}$ We cannot further reduce the window of the period of our examination because of the number of observations in our estimations.
} 
contributions of these asset classes to risk-sharing are relatively larger compared to the main results (again, with the exception of debt in the SEM model in Table 10). Finally, the observed upward bias inherent in our baseline estimates remains. Based on these final set of robustness checks, the results validate our main findings that consumption risk sharing in Korea is imperfect, asset classes have contributed favorably to consumption risk sharing with FDI retained earnings robustly contributing to buffering shocks to consumption.

\section{Conclusion}

In this paper, using provincial data on regional consumption, GDP and uniquely available data in the case of Korea on provincial net factor income flows disaggregated across the three asset classes of debt, equity and FDI reinvested earnings, we investigated how these asset channels impacted on consumption risk sharing during crises times, particularly, during the Global Financial Crisis and the European sovereign debt crisis. We documented that intranational consumption risk sharing in Korea was imperfect just as with earlier estimates in other advanced countries such as for US states and Canadian provinces, although the degree of consumption risk sharing observed in Korea is relatively lower compared to estimates found for US states and Canadian provinces which used much earlier data. We also found that net receipts of debt, equity and FDI retained earnings have all contributed favorably to consumption risk sharing during the crises with FDI retained earnings consistently contributing to risk sharing in all of our estimation results.

We also documented that much closer to the period of the financial turmoil, not only the overall degree of consumption risk sharing increased, but net contributions of the three asset classes to risk sharing also increased. There is also suggestive evidence that net equity receipts buffered more the shocks to consumption than net debt receipts. Overall, we interpret these results as evidence that one of the alleged benefits of financial integration in terms of providing consumption risk sharing opportunities is tangible and real in the context of Korea. This is important as this suggest that during crises, different asset channels can provide the insurance to mitigate shocks befalling the economy.

The findings obtained by this study can also be interpreted as providing evidence, or in a sense, vindication to Korea's pursuit of a gradual and systematic liberalization of its capital account, a process that began in 1998, just a few years after being hit by the Asian financial crisis. Our findings suggest that as a result of this policy objective, portfolio diversification opportunities had developed with beneficial welfare effects in the form of asset channels providing insurance during episodes of uncertainty in international financial markets. 


\section{References}

Anselin, L.; J. Le Gallo and H. Jayet, (2008), "Spatial Panel Econometrics," in L. Mátyás and P. Sevestre (Eds.), The Econometrics of Panel Data, Springer-Verlag, Berlin, pp. 625660.

Artis, M. and M. Hoffmann, (2008), "Financial Globalization, International Business Cycles and Consumption Risk Sharing," Scandinavian Journal of Economics, 110 (3), pp. 447-471.

Asdrubali, P.; B. Sørensen and O. Yosha, (1996), "Channels of Interstate Risk Sharing: United States 1963-1990,” Quarterly Journal of Economics, 111(4), pp.1081-1110.

Asdrubali, P. and S. Kim, (2004), "Dynamic Risksharing in the United States and Europe," 51, pp. 809-836.

Athanasouli, S. and E. van Wincoop, (2001), "Risksharing within the United States: What Have Financial Markets and Fiscal Federalism Accomplished?" Review of Economics and Statistics, 83 (4), pp. 688-698.

Bai, Y. and J. Zhang, (2012), "Financial Integration and International Risk Sharing," Journal of International Economics, 86(1), pp. 17-32.

Balli, F.; S. A. Basher and H. O. Balli, (2013), "International Income Risk-Sharing and the Global Financial Crisis of 2008-2009," Journal of Banking and Finance, 37, pp. 23032313.

Balli, F.; S. Kalemli-Ozcan and B. Sørensen, (2012), "Risk Sharing through Capital Gains," Canadian Journal of Economics, 45(2), pp. 472-492.

Bank of Korea, (2010), The Korean Economy, Available at: https://www.bok.or.kr/eng/bbs/E0000744/list.do?menuNo=400227, Retrieved on February 19, 2019.

Bank of Korea, (2012), The Korean Economy, Available at: https://www.bok.or.kr/eng/bbs/E0000744/list.do?menuNo=400227, Retrieved on February 19, 2019.

Bank of Korea, (2013), The Korean Economy, Available at: https://www.bok.or.kr/eng/bbs/E0000744/list.do?menuNo=400227, Retrieved on February 19, 2019. 
Bank of Korea, (2014), The Korean Economy, Available at: https://www.bok.or.kr/eng/bbs/E0000744/list.do?menuNo=400227, Retrieved on February 19, 2019.

Bank of Korea, (2015), The Korean Economy, Available at: https://www.bok.or.kr/eng/bbs/E0000744/list.do?menuNo=400227, Retrieved on February 19, 2019.

Bracke, T. and M, Schmitz, (2011), Channels of International Risk-sharing: Capital Gains Versus Income Flows," International Economics and Economic Policy, 8, pp. 45-78.

Bruno, V. and H. S. Shin, (2014), Assessing Macroprudential Policies: Case of South Korea," Scandinavian Journal of Economics, 116(1), pp. 128-157.

Cohen J.; Y. Ioannides and W. Thanapisitikul, (2016), "Spatial Effects and House Price Dynamics in the USA," Journal of Housing Economics, 31, pp. 1-13.

Crucini, M., (1999), "On International and National Dimensions of Risk Sharing," Review of Economics and Statistics, 81, pp. 73-84.

Crucini, M. and G. Hess, (2000), "Intranational and International Risk Sharing," in: G. Hess and E. van Wincoop (Eds.), Intranational Macroeconomics, Cambridge University Press, New York.

Demyanyk, Y.; C. Ostergaard and B. Sørensen, (2008), "Risk Sharing and Portfolio Allocation in EMU," European Economy Economic Papers, 334, Brussels, Belgium.

Elhorst, J., (2010), "Spatial Panel Models," in: M. Fischer and A. Getis (Eds.), Handbook of Applied Spatial Analysis. Springer, Berlin, pp. 377-407.

Elhorst, J., (2017), "Spatial Panel Data Analysis," in: S. Shekhar, H. Xiong and X. Zhou (Eds.) Encyclopedia of GIS, $2^{\text {nd }}$ Edition, Springer International Publishing, Cham, Switzerland, pp. 2050-2058.

Hyun, D. and S. Milcheva, (2018), "Spatial Dependence in Apartment Transaction Prices during Boom and Bust," Regional Science and Urban Economics, 68, pp. 36-45.

International Monetary Fund, (2012), "Liberalizing Capital Flows and Managing Outflows," International Monetary Fund, Washington, DC.

Kişla, G. and A. Önder, (2018), "Spatial Analysis of Sovereign Risks: The Case of Emerging Markets," Finance Research Letters, 26, pp. 47-55. 
Kose, A.; E. Prasad and M. Terrones, (2009), "Does Financial Globalization Promote Risk Sharing?" Journal of Development Economics, 89, pp. 258-270.

LeSage, J. and M. Fischer, (2008), "Spatial Growth Regressions: Model Specification, Estimation and Interpretation," Spatial Economic Analysis, 3(3), pp. 275-304.

Mélitz, J. and F. Zumer, (1999), "Interregional and International Risk Sharing and Lessons for EMU," Carnegie-Rochester Conference Series on Public Policy, 51, pp. 149-188.

Mélitz, J. and F. Zumer, (2002), "Regional Redistribution and Stabilization by the Center in Canada, France, the UK and the US: A Reassessment and New Tests," Journal of Public Economics, 86, pp. 263-286.

Mendoza, E., and V. Quadrini, (2010), "Financial Globalization, Financial Crises, and Contagion," Journal of Monetary Economics, 57, pp. 24-39.

Sørensen, B.; Y. Wu; O. Yosha and Y. Zhu, (2007), "Home Bias and International Risk Sharing: Twin Puzzles Separated at Birth," Journal of International Money and Finance, 26, pp. 587-605. 
Table 1

Consumption Smoothing and the Buffering Effects of Various Net Factor Income Flows:

Baseline Results: Non-spatial Models

\begin{tabular}{|c|c|c|c|c|}
\hline & $(1)$ & A. Equity & B. Interest & $\begin{array}{c}(4) \\
\text { C. Foreign Direct Investment (FDI) }\end{array}$ \\
\hline & $\Delta \log (\dddot{C})_{j t}$ & 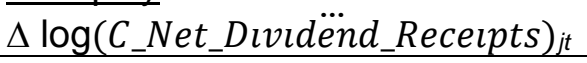 & 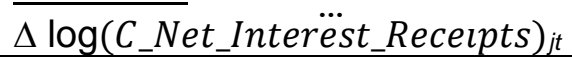 & $\overline{\Delta \log \left(C_{-} N e t \_R e c e i \dddot{p t} s_{-} F D I \_R e \_E\right)_{j t}}$ \\
\hline$\Delta \log (R G \dddot{D} P p c)_{j t}$ & $\begin{array}{c}0.522^{* * *} \\
(0.066)\end{array}$ & $\begin{array}{c}0.562^{* * *} \\
(0.141)\end{array}$ & $\begin{array}{c}0.614^{* * *} \\
(0.142)\end{array}$ & $\begin{array}{c}0.633^{* * *} \\
(0.128)\end{array}$ \\
\hline Observations & 128 & 128 & 128 & 128 \\
\hline
\end{tabular}

Notes: (a) For the definition of the variables refer to the main text.

(b) numbers in parentheses are standard errors.

(c) ${ }^{* * *},{ }^{* *}$, and ${ }^{*}$ denote significance at the $1 \%, 5 \%$ and $10 \%$ levels, respectively. 
Table 2

LM Test Results for Choosing Between Spatial and Non-spatial Models

\begin{tabular}{cccc}
\multicolumn{4}{c}{ Panel A. Dependent variable: $\Delta \log (\dddot{C})_{j t}$} \\
\hline & $\begin{array}{c}\text { Province } \\
\text { fixed effect }\end{array}$ & $\begin{array}{c}\text { Time-Period } \\
\text { fixed effect }\end{array}$ & $\begin{array}{c}\text { Province and Time-Period } \\
\text { fixed effect }\end{array}$ \\
\hline LM spatial lag & 0.151 & 1.482 & 4.027 \\
& {$[0.698]$} & {$[0.223]$} & {$[0.045]$} \\
LM spatial error & 0.665 & 1.559 & 4.386 \\
& {$[0.415]$} & {$[0.212]$} & {$[0.036]$} \\
Robust LM spatial lag & 0.570 & 0.010 & 0.009 \\
& {$[0.450]$} & {$[0.920]$} & {$[0.924]$} \\
Robust LM spatial error & 1.085 & 0.087 & 0.368 \\
& {$[0.298]$} & {$[0.768]$} & {$[0.544]$} \\
\hline
\end{tabular}

Notes: (a). Numbers in square brackets are probability values.

(b). For the definition of the variable refer to the main text.

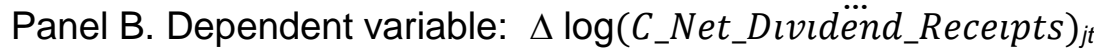

\begin{tabular}{cccc}
\hline & $\begin{array}{c}\text { Province } \\
\text { fixed effect }\end{array}$ & $\begin{array}{c}\text { Time-Period } \\
\text { fixed effect }\end{array}$ & $\begin{array}{c}\text { Province and Time-Period } \\
\text { fixed effect }\end{array}$ \\
\hline LM spatial lag & 0.872 & 3.297 & 4.144 \\
& {$[0.350]$} & {$[0.069]$} & {$[0.042]$} \\
LM spatial error & 0.708 & 2.646 & 3.458 \\
& {$[0.400]$} & {$[0.104]$} & {$[0.063]$} \\
Robust LM spatial lag & 0.230 & 1.392 & 1.375 \\
& {$[0.631]$} & {$[0.238]$} & {$[0.241]$} \\
Robust LM spatial error & 0.066 & 0.741 & 0.688 \\
& {$[0.797]$} & {$[0.390]$} & {$[0.407]$} \\
\hline
\end{tabular}

Notes: (a). Numbers in square brackets are probability values.

(b). For the definition of the variable refer to the main text.

Panel C. Dependent variable: $\Delta \log \left(C_{-} N \text { et_Interest_Recelpts }\right)_{j t}$

\begin{tabular}{cccc}
\hline & $\begin{array}{c}\text { Province } \\
\text { fixed effect }\end{array}$ & $\begin{array}{c}\text { Time-Period } \\
\text { fixed effect }\end{array}$ & $\begin{array}{c}\text { Province and Time-Period } \\
\text { fixed effect }\end{array}$ \\
\hline LM spatial lag & 1.481 & 3.859 & 5.618 \\
& {$[0.224]$} & {$[0.049]$} & {$[0.018]$} \\
LM spatial error & 0.837 & 2.707 & 4.122 \\
& {$[0.360]$} & {$[0.100]$} & {$[0.042]$} \\
Robust LM spatial lag & 1.658 & 3.455 & 3.984 \\
& {$[0.198]$} & {$[0.063]$} & {$[0.046]$} \\
Robust LM spatial error & 1.014 & 2.303 & 2.487 \\
& {$[0.314]$} & {$[0.129]$} & {$[0.115]$} \\
\hline
\end{tabular}

Notes: (a). Numbers in square brackets are probability values.

(b). For the definition of the variable refer to the main text. 
Panel D. $\Delta \log \left(C_{-} N e t_{-} R e c e i \dddot{p t} s_{-} F D I_{-} R e_{-} E\right)_{j t}$

Province Time-Period Province and Time-Period fixed effect fixed effect

\begin{tabular}{cccc}
\hline LM spatial lag & 1.511 & 4.287 & 5.516 \\
& {$[0.219]$} & {$[0.038]$} & {$[0.019]$} \\
LM spatial error & 1.330 & 3.095 & 4.197 \\
& {$[0.249]$} & {$[0.079]$} & {$[0.041]$} \\
Robust LM spatial lag & 0.184 & 2.673 & 2.620 \\
& {$[0.668]$} & {$[0.102]$} & {$[0.106]$} \\
Robust LM spatial error & 0.003 & 1.480 & 1.301 \\
& {$[0.954]$} & {$[0.224]$} & {$[0.254]$} \\
\hline
\end{tabular}

Notes: (a) Numbers in square brackets are probability values.

(b) For the definition of the variable refer to the main text. 
Table 3

Consumption Smoothing and the Buffering Effects of Various Net Factor Income Flows:

Main Results: Spatial Models

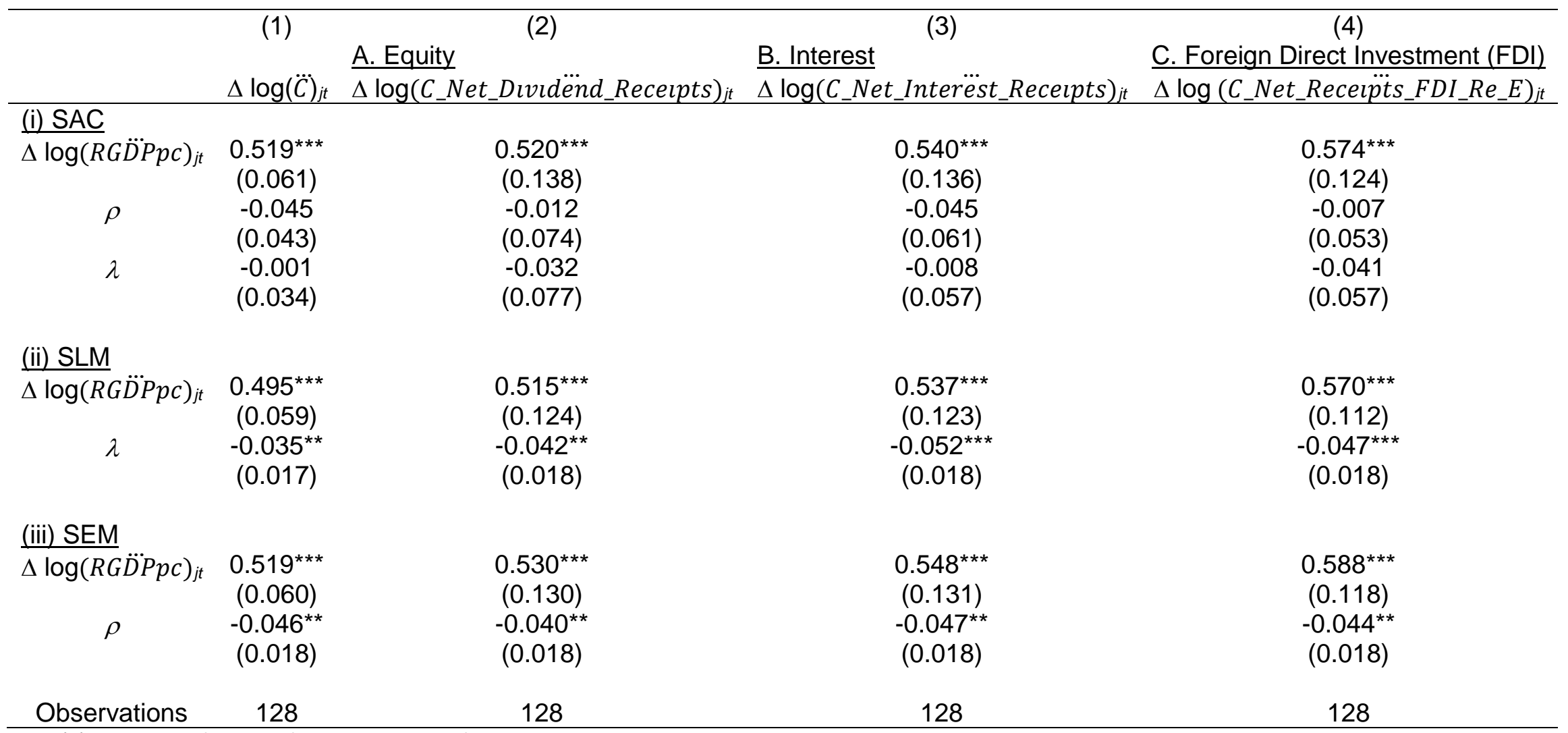

Notes: (a) For the definition of the variables refer to the main text.

(b) numbers in parentheses are standard errors.

(c) ${ }^{* * *},{ }^{* *}$, and ${ }^{*}$ denote significance at the $1 \%, 5 \%$ and $10 \%$ levels, respectively.

(d) The stationarity bounds of $\rho$ and $\lambda$ are $1 / \omega_{\min }=-0.195$ and $1 / \omega_{\max }=0.085$. 
Table 4

Consumption Smoothing and the Buffering Effects of Various Net Factor Income Flows:

(Robustness Test Results of Spatial Models: Inverse Squared Distance as Spatial Weight)

\begin{tabular}{|c|c|c|c|c|}
\hline & (1) & A. Equity & B. Interest & $\begin{array}{l}\text { (4) } \\
\text { C. Foreign Direct Investment (FDI) }\end{array}$ \\
\hline & $\Delta \log (\dddot{C})_{j t}$ & 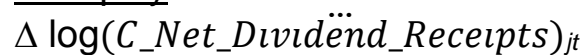 & $\Delta \log \left(C_{-} N e t \text { Interest_Recelpts }\right)_{j t}$ & $\Delta \log \left(C_{-} \text {Net_Recelpts_FDI_Re_E }\right)_{j t}$ \\
\hline \multicolumn{5}{|l|}{ (i) $\mathrm{SAC}$} \\
\hline$\Delta \log (R G \dddot{D P} P p)_{j t}$ & $\begin{array}{c}0.465^{\star * *} \\
(0.061)\end{array}$ & $\begin{array}{c}0.531^{* * *} \\
(0.129)\end{array}$ & $\begin{array}{c}0.565^{\star * *} \\
(0.129)\end{array}$ & $\begin{array}{c}0.586^{* \star *} \\
(0.117)\end{array}$ \\
\hline \multirow[t]{2}{*}{$\rho$} & 0.010 & 0.006 & 0.006 & 0.007 \\
\hline & $(0.007)$ & $(0.011)$ & $(0.011)$ & $(0.010)$ \\
\hline \multirow[t]{2}{*}{$\lambda$} & -0.016 & -0.011 & -0.013 & -0.013 \\
\hline & $(0.006)$ & $(0.011)$ & $(0.009)$ & $(0.009)$ \\
\hline \multicolumn{5}{|l|}{ (ii) SLM } \\
\hline \multirow[t]{2}{*}{ 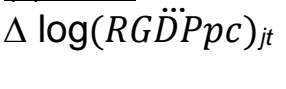 } & $0.498^{* * \star}$ & $0.543^{\star * \star}$ & $0.573^{\star \star \star}$ & $0.603^{\star * *}$ \\
\hline & $(0.059)$ & $(0.127)$ & $(0.127)$ & $(0.115)$ \\
\hline \multirow{2}{*}{$\lambda$} & $-0.008^{* *}$ & -0.005 & $-0.009^{*}$ & $-0.007^{\star \star}$ \\
\hline & $(0.004)$ & $(0.005)$ & $(0.005)$ & $(0.005)$ \\
\hline \multicolumn{5}{|l|}{ (iii) SEM } \\
\hline \multirow[t]{2}{*}{$\Delta \log (R G \dddot{D P} P p)_{j t}$} & $0.507^{* * *}$ & $0.548^{* * *}$ & $0.576^{\star \star *}$ & $0.609^{* * *}$ \\
\hline & $(0.060)$ & $(0.128)$ & $(0.129)$ & $(0.116)$ \\
\hline \multirow[t]{2}{*}{$\rho$} & $-0.010^{* *}$ & -0.004 & -0.007 & 0.006 \\
\hline & $(0.005)$ & $(0.005)$ & $(0.005)$ & $(0.005)$ \\
\hline Observations & 128 & 128 & 128 & 128 \\
\hline
\end{tabular}

Notes: (a) For the definition of the variables refer to the main text.

(b) numbers in parentheses are standard errors.

(c) ${ }^{* * *},{ }^{* *}$, and ${ }^{*}$ denote significance at the $1 \%, 5 \%$ and $10 \%$ levels, respectively.

(d) The stationarity bounds of $\rho$ and $\lambda$ are $1 / \omega_{\min }=-0.039$ and $1 / \omega_{\max }=0.036$. 
Table 5

Consumption Smoothing and the Buffering Effects of Various Net Factor Income Flows:

(Robustness Test Results of Spatial Models: K Nearest Neighbor as Spatial Weight, K = 2)

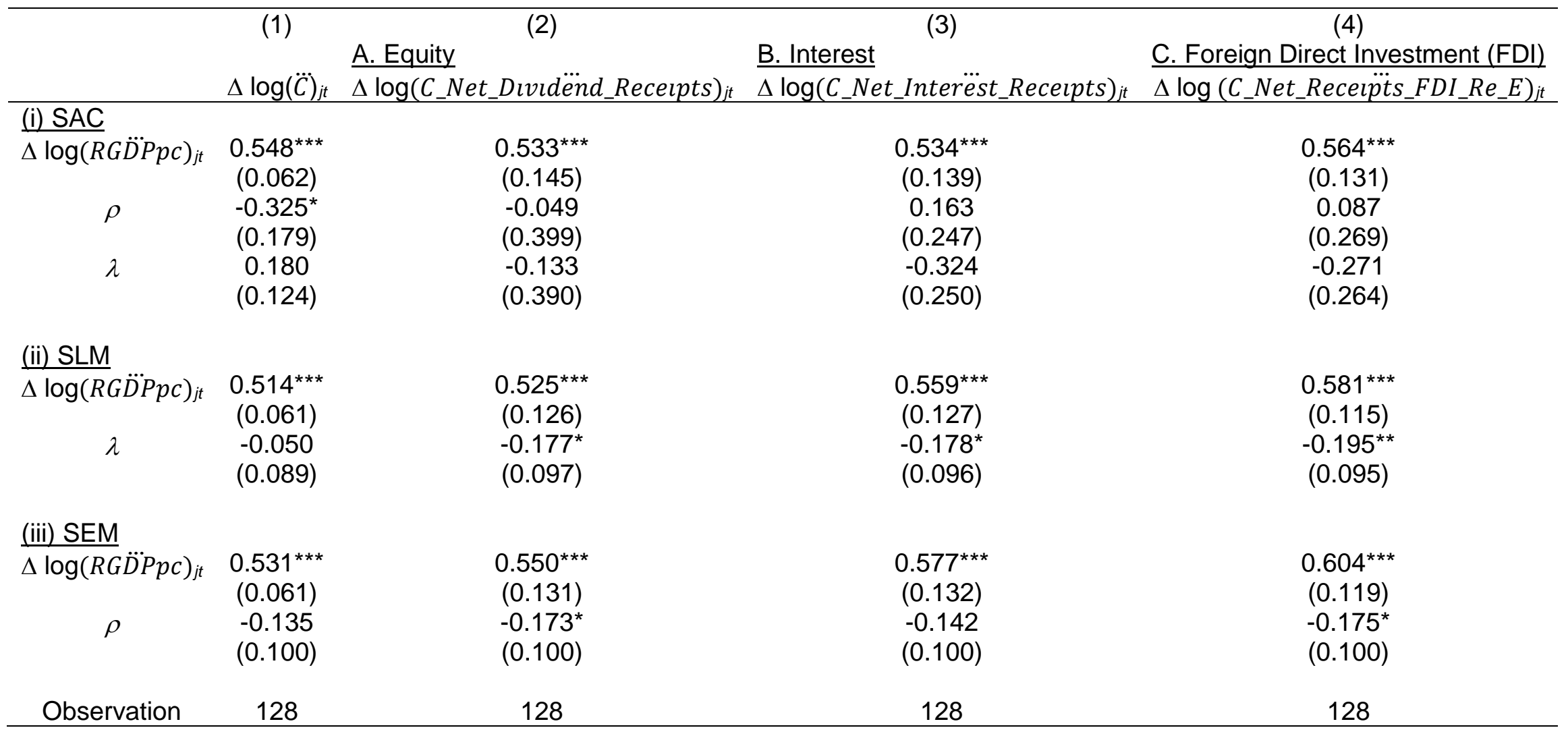

Notes: (a) For the definition of the variables refer to the main text.

(b) numbers in parentheses are standard errors.

(c) ${ }^{* * *},{ }^{* *}$, and ${ }^{*}$ denote significance at the $1 \%, 5 \%$ and $10 \%$ levels, respectively.

(d) The stationarity bounds of $\rho$ and $\lambda$ are $1 / \omega_{\min }=-1.035$ and $1 / \omega_{\max }=1.0$. 
Table 6

Consumption Smoothing and the Buffering Effects of Various Net Factor Income Flows:

(Robustness Test Results of Spatial Models: K Nearest Neighbor as Spatial Weight, K = 3)

\begin{tabular}{|c|c|c|c|c|}
\hline & (1) & A. Equity & B. Interest & $\begin{array}{c}(4) \\
\text { C. Foreign Direct Investment (FDI) }\end{array}$ \\
\hline & $\Delta \log (\dddot{C})_{j t}$ & $\Delta \log \left(C_{-} N \text { Net_Dıvıdênd_Recelpts }\right)_{j t}$ & $\Delta \log \left(C_{-} N e t \text { Interest_Recelpts }\right)_{j t}$ & $\overrightarrow{\Delta \log \left(C_{-} \text {Net_Receipts_FDI_Re_E }\right)_{j t}}$ \\
\hline \multicolumn{5}{|c|}{ 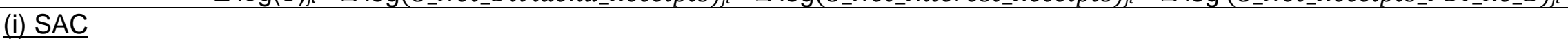 } \\
\hline$\triangle \log (R G \dddot{D} P p c)_{j t}$ & $\begin{array}{c}0.541^{* * *} \\
(0.062)\end{array}$ & $\begin{array}{c}0.504^{* * *} \\
(0.139)\end{array}$ & $\begin{array}{c}0.546^{* * *} \\
(0.140)\end{array}$ & $\begin{array}{c}0.583^{* * *} \\
(0.132)\end{array}$ \\
\hline$\rho$ & $\begin{array}{l}-0.327 \\
(0.269)\end{array}$ & $\begin{array}{c}0.080 \\
(0.424)\end{array}$ & $\begin{array}{c}0.171 \\
(0354)\end{array}$ & $\begin{array}{l}0.026 \\
0.433)\end{array}$ \\
\hline$\lambda$ & $\begin{array}{c}0.126 \\
(0.213)\end{array}$ & $\begin{array}{l}(0.4<4) \\
-0.390 \\
(0.460)\end{array}$ & $\begin{array}{l}(0.354) \\
-0.412 \\
(0.401)\end{array}$ & $\begin{array}{l}(0.433) \\
-0.287 \\
(0.452)\end{array}$ \\
\hline \multicolumn{5}{|l|}{ (ii) SLM } \\
\hline$\triangle \log (R G \dddot{D P} P p c)_{j t}$ & $\begin{array}{l}0.513^{* * *} \\
(0.060)\end{array}$ & $\begin{array}{l}0.513^{* * *} \\
(0.124)\end{array}$ & $\begin{array}{l}0.562^{\star * *} \\
(0.127)\end{array}$ & $\begin{array}{l}0.586^{* * *} \\
(0.114)\end{array}$ \\
\hline$\lambda$ & $\begin{array}{l}-0.112 \\
(0.115)\end{array}$ & $\begin{array}{l}-0.308^{* *} \\
(0.125)\end{array}$ & $\begin{array}{l}-0.240^{*} \\
(0.124)\end{array}$ & $\begin{array}{l}-0.262^{* *} \\
(0.124)\end{array}$ \\
\hline \multicolumn{5}{|l|}{ (iii) SEM } \\
\hline$\triangle \log (R G M P P p c)_{j t}$ & $\begin{array}{l}0.532^{* * *} \\
(0.061)\end{array}$ & $\begin{array}{l}0.533^{* * *} \\
(0.130)\end{array}$ & $\begin{array}{l}0.577^{\star * \star} \\
(0.131)\end{array}$ & $\begin{array}{l}0.607^{* * *} \\
(0.118)\end{array}$ \\
\hline$\rho$ & $\begin{array}{l}-0.195 \\
(0.127)\end{array}$ & $\begin{array}{l}-0.289^{* *} \\
(0.128)\end{array}$ & $\begin{array}{l}-0.190 \\
(0.126)\end{array}$ & $\begin{array}{l}-0.231^{*} \\
(0.127)\end{array}$ \\
\hline Observation & 128 & 128 & 128 & 128 \\
\hline
\end{tabular}

Notes: (a) For the definition of the variables refer to the main text.

(b) numbers in parentheses are standard errors.

(c) ${ }^{* * *},{ }^{* *}$, and ${ }^{*}$ denote significance at the $1 \%, 5 \%$ and $10 \%$ levels, respectively.

(d) The stationarity bounds of $\rho$ and $\lambda$ are $1 / \omega_{\min }=-1.533$ and $1 / \omega_{\max }=1.0$. 
Table 7

Consumption Smoothing and the Buffering Effects of Various Net Factor Income Flows:

(Robustness Test Results of Spatial Models: Inverse Distance with Cutoff < $250 \mathrm{KMs}$ as Spatial Weight)

\begin{tabular}{|c|c|c|c|c|}
\hline & $(1)$ & A. Equity & B. Interest & $\begin{array}{c}(4) \\
\text { C. Foreian Direct Investment (FDI) }\end{array}$ \\
\hline & $\Delta \log (\dddot{C})_{j t}$ & 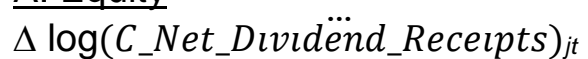 & $\Delta \log \left(C_{-} N e t \text { Interest_Recelpts }\right)_{j t}$ & $\Delta \log \left(C_{-} N_{\text {Net_Recelpts }} F D I_{-} R e_{-} E\right)_{j t}$ \\
\hline \multicolumn{5}{|l|}{ (i) $\mathrm{SAC}$} \\
\hline$\triangle \log (R G \dddot{D P P} p c)_{j t}$ & $\begin{array}{c}0.517^{* * *} \\
(0.060)\end{array}$ & $\begin{array}{c}0.529^{* * *} \\
(0.136)\end{array}$ & $\begin{array}{c}0.556^{* * *} \\
(0.132)\end{array}$ & $\begin{array}{c}0.578^{\star \star \star} \\
(0.121)\end{array}$ \\
\hline$\rho$ & $\begin{array}{l}-7.380^{* * *} \\
(2668)\end{array}$ & 0.682 & 1.445 & 1.769 \\
\hline$\lambda$ & $\begin{array}{l}3.2488^{*} \\
(1.7191)\end{array}$ & $\begin{array}{l}(0.200) \\
-3.194 \\
(5.929)\end{array}$ & $\begin{array}{l}-4.688 \\
(4.505)\end{array}$ & $\begin{array}{l}(3.403) \\
-4.651 \\
(4.134)\end{array}$ \\
\hline \multicolumn{5}{|l|}{ (ii) SLM } \\
\hline $\begin{array}{c}\Delta \log (R G M \ddot{D P} p c)_{j t} \\
\lambda\end{array}$ & $\begin{array}{c}0.507^{\star * *} \\
(0.060) \\
-2.079 \\
(1.567)\end{array}$ & $\begin{array}{c}0.534^{\star * *} \\
(0.126) \\
-2.530 \\
(1.693)\end{array}$ & $\begin{array}{c}0.566^{\star * *} \\
(0.126) \\
-3.288^{*} \\
(1.709)\end{array}$ & $\begin{array}{l}0.594^{* * *} \\
(0.114) \\
-2.894^{*} \\
(1.684)\end{array}$ \\
\hline \multicolumn{5}{|l|}{ (iii) SEM } \\
\hline $\begin{array}{c}\Delta \log (R G M P P c)_{j t} \\
\rho\end{array}$ & $\begin{array}{c}0.524^{\star * \star} \\
(0.060) \\
-3.032^{*} \\
(1.751)\end{array}$ & $\begin{array}{c}0.543^{* * *} \\
(0.129) \\
-2.274 \\
(1.723)\end{array}$ & $\begin{array}{c}0.575^{\star \star *} \\
(0.130) \\
-2.787 \\
(1.743)\end{array}$ & $\begin{array}{c}0.607^{\star * *} \\
(0.117) \\
-2.500^{* *} \\
(1.733)\end{array}$ \\
\hline Observation & 128 & 128 & 128 & 128 \\
\hline
\end{tabular}

Notes: (a) For the definition of the variables refer to the main text.

(b) numbers in parentheses are standard errors.

(c) ${ }^{* * *},{ }^{* *}$, and ${ }^{*}$ denote significance at the $1 \%, 5 \%$ and $10 \%$ levels, respectively.

(d) The stationarity bounds of $\rho$ and $\lambda$ are $1 / \omega_{\min }=-17.355$ and $1 / \omega_{\max }=10.073$. 
Table 8

Consumption Smoothing and the Buffering Effects of Various Net Factor Income Flows:

(Robustness Test Results of Spatial Models: Inverse Distance with Cutoff < 350 KMs as Spatial Weight)

\begin{tabular}{|c|c|c|c|c|}
\hline & (1) & (2) & (3) & $\begin{array}{c}(4) \\
\text { C. Foreian Direct Investment (FDI) }\end{array}$ \\
\hline & $\Delta \log (\dddot{C})_{i t}$ & $\frac{\text { A. Equity }}{\Delta \operatorname{lng}(C N e t}$ Duvde. & $\frac{\text { B. Interest }}{10}$ & C. Foreign Direct Investment (FDI) \\
\hline \multicolumn{5}{|l|}{ (i) $\mathrm{SAC}$} \\
\hline$\Delta \log (R G \dddot{D P} P p c)_{j t}$ & $\begin{array}{c}0.520^{* * *} \\
(0.061)\end{array}$ & $\begin{array}{l}0.524^{* * *} \\
(0.139)\end{array}$ & $\begin{array}{c}0.546^{* * *} \\
(0.135)\end{array}$ & $\begin{array}{c}0.578^{* * *} \\
(0.124)\end{array}$ \\
\hline \multirow[t]{2}{*}{$\rho$} & -4.738 & -0.860 & -0.266 & -0.115 \\
\hline & (3.853) & (7.013) & (5.085) & (4.809) \\
\hline \multirow[t]{2}{*}{$\lambda$} & 0.794 & -2.894 & -4.318 & -3.894 \\
\hline & $(2.964)$ & $(7.350)$ & $(5.569)$ & (5.252) \\
\hline \multicolumn{5}{|l|}{ (ii) SLM } \\
\hline 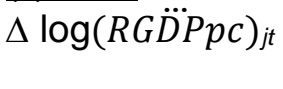 & $\begin{array}{c}0.498^{* * *} \\
(0.060)\end{array}$ & $\begin{array}{c}0.520^{* * *} \\
(0.125)\end{array}$ & $\begin{array}{c}0.545^{\star * *} \\
(0.124)\end{array}$ & $\begin{array}{c}0.578^{* * *} \\
(0.113)\end{array}$ \\
\hline \multirow[t]{2}{*}{$\lambda$} & $-2.945^{\star}$ & $-3.638^{* *}$ & $-4.546^{* * *}$ & $-3.994^{\star *}$ \\
\hline & (1.608) & (1.730) & (1.733) & $(1.714)$ \\
\hline \multicolumn{5}{|l|}{ (iii) SEM } \\
\hline \multirow[t]{2}{*}{$\triangle \log (R G \dddot{D} P p c)_{j t}$} & $0.518^{* * *}$ & $0.535^{\star * *}$ & $0.556^{\star * *}$ & $0.595^{\star * \star}$ \\
\hline & $(0.060)$ & $(0.130)$ & $(0.131)$ & $(0.118)$ \\
\hline \multirow[t]{2}{*}{$\rho$} & $-3.768^{* *}$ & $-3.455^{\star}$ & $-4.100^{* * *}$ & $-3.680^{\star *}$ \\
\hline & $(1.772)$ & $(1.765)$ & $(1.778)$ & $(1.771)$ \\
\hline Observation & 128 & 128 & 128 & 128 \\
\hline
\end{tabular}

Notes: (a) For the definition of the variables refer to the main text.

(b) numbers in parentheses are standard errors.

(c) ${ }^{* * *},{ }^{* *}$, and ${ }^{*}$ denote significance at the $1 \%, 5 \%$ and $10 \%$ levels, respectively.

(d) The stationarity bounds of $\rho$ and $\lambda$ are $1 / \omega_{\min }=-17.467$ and $1 / \omega_{\max }=8.481$. 
Table 9

Consumption Smoothing and the Buffering Effects of Various Net Factor Income Flows:

(Robustness Test Results of Spatial Models: Inverse Distance Spatial Weight, 2008-2012 Time Period)

\begin{tabular}{|c|c|c|c|c|}
\hline & (1) & A. Equity & B. Interest & $\begin{array}{l}(4) \\
\text { C. Foreian Direct Investment (FDI) }\end{array}$ \\
\hline & $\Delta \log (\dddot{C})_{j t}$ & $\overline{\Delta \log \left(C_{2} N\right.} N e t$ Divıldend_Recelpts $)_{\text {it }}$ & $\Delta \log \left(C_{-} N e t \text { Interest_Recelpts }\right)_{j t}$ & $\Delta \log \left(C_{-} \text {Net_Recelp̈ts_FDI_Re_E }\right)_{j t}$ \\
\hline (i) SAC & & & & \\
\hline$\triangle \log (R G \dddot{D} P p c)_{j t}$ & $\begin{array}{c}0.380^{* * *} \\
(0.066)\end{array}$ & $\begin{array}{c}0.518^{* * *} \\
(0.159)\end{array}$ & $\begin{array}{c}0.433^{\star * *} \\
(0.167)\end{array}$ & $\begin{array}{c}0.515^{\star * *} \\
(0.149)\end{array}$ \\
\hline$\rho$ & $-0.115^{\star \star *}$ & 0.006 & -0.012 & 0.001 \\
\hline & $(0.024)$ & $(0.064)$ & $(0.086)$ & $(0.060)$ \\
\hline$\lambda$ & $0.051^{* * *}$ & -0.038 & -0.050 & -0.049 \\
\hline & $(0.013)$ & $(0.075)$ & $(0.092)$ & $(0.069)$ \\
\hline (ii) SLM & & & & \\
\hline$\triangle \log (R G \dddot{D} P p c)_{j t}$ & $0.387^{* * *}$ & $0.519^{\star * *}$ & $0.435^{\star \star \star}$ & $0.515^{\star \star \star}$ \\
\hline & $(0.071)$ & $(0.153)$ & $(0.159)$ & $(0.144)$ \\
\hline$\lambda$ & $-0.040^{*}$ & -0.033 & $-0.059^{\star \star \star}$ & $-0.048^{\star *}$ \\
\hline & $(0.022)$ & $(0.022)$ & $(0.023)$ & $(0.023)$ \\
\hline (iii) SEM & & & & \\
\hline$\triangle \log (R G \dddot{D P} P p c)_{j t}$ & $0.406^{* * *}$ & $0.520^{\star * *}$ & $0.416^{* *}$ & $0.515^{\star \star *}$ \\
\hline & $(0.072)$ & $(0.157)$ & $(0.167)$ & $(0.149)$ \\
\hline$\rho$ & $-0.051^{* *}$ & -0.028 & $-0.056^{\star *}$ & $-0.045^{*}$ \\
\hline & $(0.023)$ & $(0.023)$ & $(0.023)$ & $(0.023)$ \\
\hline Observations & 80 & 80 & 80 & 80 \\
\hline
\end{tabular}

Notes: (a) For the definition of the variables refer to the main text.

(b) numbers in parentheses are standard errors.

(c) ${ }^{* * *},{ }^{* *}$, and ${ }^{*}$ denote significance at the $1 \%, 5 \%$ and $10 \%$ levels, respectively.

(d) The stationarity bounds of $\rho$ and $\lambda$ are $1 / \omega_{\min }=-0.195$ and $1 / \omega_{\max }=0.085$. 
Table 10

Consumption Smoothing and the Buffering Effects of Various Net Factor Income Flows:

(Robustness Test Results of Spatial Models: Inverse Distance Spatial Weight, 2008-2011 Time Period)

\begin{tabular}{|c|c|c|c|c|}
\hline & (1) & (2) & (3) & $\begin{array}{c}(4) \\
0\end{array}$ \\
\hline & . & A. Equity & B. Interest & \\
\hline & $\Delta \log (\dddot{C})_{j t}$ & $\Delta \log \left(C_{-} \text {Net_Dıvıdënd_Receıpts }\right)_{j t}$ & $\Delta \log \left(C_{-} \text {Net_Interëst_Recelpts }\right)_{j t}$ & $\Delta \log \left(C \_N e t \_R e c e i \dddot{p t s} \_F D I \_R e \_E\right)_{j t}$ \\
\hline (i) SAC & & & & \\
\hline$\Delta \log (R G \ddot{D P} p c)_{j t}$ & $\begin{array}{c}0.412^{\star * *} \\
(0.067)\end{array}$ & $\begin{array}{c}0.537^{\star * *} \\
(0.174)\end{array}$ & $\begin{array}{l}0.437^{* *} \\
(0185)\end{array}$ & $0.514^{* * *}$ \\
\hline$\rho$ & $-0.128^{\star * \star}$ & 0.010 & -0.010 & 0.005 \\
\hline & $(0.022)$ & $(0.065)$ & $(0.090)$ & $(0.063)$ \\
\hline$\lambda$ & $0.057^{* \star *}$ & -0.037 & -0.050 & -0.049 \\
\hline & $(0.011)$ & $(0.078)$ & $(0.098)$ & $(0.074)$ \\
\hline (ii) SLM & & & & \\
\hline 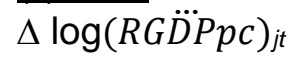 & $0.417^{\star * *}$ & $0.539^{\star \star *}$ & $0.438^{* *}$ & $0.516^{\star * \star}$ \\
\hline & $(0.077)$ & $(0.168)$ & $(0.176)$ & $(0.159)$ \\
\hline$\lambda$ & -0.038 & -0.028 & $-0.058^{* *}$ & $-0.044^{*}$ \\
\hline & $(0.024)$ & $(0.025)$ & $(0.026)$ & $(0.025)$ \\
\hline (iii) SEM & & & & \\
\hline$\Delta \log (R G \dddot{D P} p c)_{j t}$ & $0.443^{\star \star \star}$ & $0.544^{\star * *}$ & $0.422^{* *}$ & $0.519^{* * *}$ \\
\hline & $(0.077)$ & $(0.171)$ & $(0.185)$ & $(0.165)$ \\
\hline$\rho$ & $-0.054^{* *}$ & -0.023 & $-0.054^{\star *}$ & -0.041 \\
\hline & $(0.026)$ & $(0.025)$ & $(0.026)$ & $(0.026)$ \\
\hline Observations & 64 & 64 & 64 & 64 \\
\hline
\end{tabular}

Notes: (a) For the definition of the variables refer to the main text.

(b) numbers in parentheses are standard errors.

(c) ${ }^{* * *},{ }^{* *}$, and ${ }^{*}$ denote significance at the $1 \%, 5 \%$ and $10 \%$ levels, respectively.

(d) The stationarity bounds of $\rho$ and $\lambda$ are $1 / \omega_{\min }=-0.195$ and $1 / \omega_{\max }=0.085$. 